\title{
Carnets
}

Revue électronique d'études françaises de l'APEF

Première Série - 1 Numéro Spécial | 2009

Cultures littéraires : nouvelles performances \& développement

\section{Utopia e (Des)encanto em Vivre à Madère de Jacques Chardonne}

\section{Ana Isabel Moniz}

\author{
(2) OpenEdition \\ Journals \\ Edição electrónica \\ URL: http://journals.openedition.org/carnets/4021 \\ DOI: 10.4000/carnets.4021 \\ ISSN: 1646-7698 \\ Editora \\ APEF
}

Edição impressa

Data de publição: 1 Junho 2009

Paginação: 289-297

\section{Refêrencia eletrónica}

Ana Isabel Moniz, «Utopia e (Des)encanto em Vivre à Madère de Jacques Chardonne », Carnets

[Online], Première Série - 1 Numéro Spécial | 2009, posto online no dia 16 junho 2018, consultado o 01 maio 2019. URL : http://journals.openedition.org/carnets/4021 ; DOI : 10.4000/carnets.4021

\section{(c) (i) (8)}

Carnets est mis à disposition selon les termes de la licence Creative Commons - Atribution - Pas d'utilisation commerciale 4.0 International. 


\title{
UTOPIA E (DES)ENCANTO EM VIVRE À MADĖRE DE JACQUES CHARDONNE
}

\author{
ANA ISABEL MONIZ \\ Universidade da Madeira \\ anamoniz@uma.pt
}

\begin{abstract}
Resumo
Se, como afirma Jacques Chardonne, "l'éden, le paradis perdu, l'âge d'or, le bonheur, c'est une singulière idée chez les hommes", procuraremos compreender de que forma a ideia utópica de éden ou de perfeição se poderá encontrar na obra de Jacques Chardonne intitulada Vivre à Madère, publicada em Paris em 1953. Poderá a ilha, neste caso particular, a Madeira, aproximar-se da noção utópica de «lugar ideal», na esteira de Thomas More ou, pelo contrário, irá o protagonista, aquando da sua deslocação à ilha, confrontar-se com uma experiência de desencanto? Tentaremos reflectir acerca destas questões procurando o seu enquadramento na perspectiva literária das relações entre Utopia e Viagem, pelo facto de nela se fundar a estrutura matricial do género utópico, assim como se procurará estabelecer uma ligação com outras áreas do saber, nomeadamente, a Filosofia, na forma como o narrador irá questionar a própria vida.
\end{abstract}

\begin{abstract}
If, as Jacques Chardonne claims, "l'éden, le paradis perdu, l'âge d'or, le bonheur, c'est une singulière idée chez les hommes", my aim is to uncover and understand in what way the utopian idea of Eden or of perfection may be found in the work by Jacques Chardonne entitled Vivre à Madère and published in Paris in 1953. Is it possible that the island, in this case Madeira, may come close to the utopian idea of 'ideal place', in the wake of Thomas More or, on the contrary, is it the case that the protagonist, when visiting the island, will be confronted with an experience of disenchantment? It is the aim of this paper to reflect upon theses issues while seeking, on the one hand, to place them within a literary perspective in terms of the relation between Utopia and Travel and, on the other, endeavour to establish a link to other areas of knowledge, namely Philosophy, via the way the narrator questions life itself.
\end{abstract}

Palavras-chave: Real, Ficção, Viagem, Conhecimento

Keywords: Real, Fiction, Travel, Knowledge

Ana Isabel Moniz, "Utopia e (Des)encanto em Vivre à Madère de Jacques Chardonne", Carnets, Cultures littéraires: nouvelles performances et développement, no spécial, automne / hiver 2009, pp. 289-297. 
L'éden, le paradis perdu, l'âge d'or, le bonheur, c'est une singulière idée chez les hommes.

Jacques Chardonne, Vivre à Madère

"Un homme plein de passion et de désordre qui ne parle que de raison" (Chardonne, 1953: 222) é uma frase extraída do livro Vivre à Madère, de Jacques Chardonne, publicado em Paris, em 1953, e que poderá contribuir para dar a conhecer a personalidade de um autor "mal connu" (Vandromme, 2003: 19), nascido em Barbezieux, Charente, em 1884, e que Paul Morand considerou como "o mais excêntrico dos clássicos" (Guitard-Auviste, 2000: 9) ${ }^{1}$.

Obras como L'Épithalame, o primeiro romance, publicado em 1921, Claire, contemplado com o Grande Prémio da Academia Francesa, os três volumes de Destinées sentimentales, bem como Bonheur de Barbezieux ter-lhe-ão valido a designação de "romancier du couple" (Guitard-Auviste, 2000: 9) definido, contudo, pelo autor como "cette énigme: I'union difficile de deux êtres mal assortis parce qu'ils sont d'espèce différente. [...] Le ciel et l'enfer dans la même mixture"².

Jacques Chardonne irá dedicar-se a registar, através de nuances, a complexidade dos sentimentos que impede, não raras vezes, a felicidade a dois, deixando vislumbrar uma personalidade contraditória, dividida entre uma ardente angústia e a serenidade que, finalmente, acaba por deixar transparecer na quase totalidade da sua produção literária ${ }^{3}$ : "Ce qui est pénible c'est de mourir dans le désordre et avant d'avoir tout dit" ${ }^{4}$. A voz interiorizada de um eu, modelada pelas meditações de um moralista, aflora no registo de ensaios e de reflexões que viriam a orientar uma outra fase da sua vasta obra, e de que podem ser exemplo L'amour, c'est beaucoup plus que l'amour e Matinales ou Demi-jour.

Se, como afirma Jacques Chardonne, "l'éden, le paradis perdu, l'âge d'or, le bonheur, c'est une singulière idée chez les hommes" (Chardonne, 1953: 11), procuraremos ver de que forma a ideia utópica de éden ou de perfeição se poderá encontrar em Vivre à Madère, ficando, contudo, fora do nosso propósito a problematização do conceito de utopia ${ }^{5}$. Significa que se privilegiará o seu enquadramento na perspectiva literária das relações entre utopia e viagem, tendo em conta a relevância que esta assume pelo facto de nela se fundar

\footnotetext{
${ }^{1}$ Paul Morand citado por Ginette Guitard-Auviste (2000). Jacques Chardonne ou l'incandescence sous le givre. Paris: Albin Michel.

2 Jacques Chardonne citado por Ginette Guitard-Auviste, Jacques Chardonne ou l'incandescence sous le givre, op. cit., p. 147. Jacques Chardonne abordará as relações conjugais sob várias formas: o divórcio em Chants du bienheureux, de 1927, as crianças em Les Destinées sentimentales, de 1934, e o amor-paixão em Romanesques, de 1938.

${ }^{3}$ Cf. Ginette Guitard-Auviste, Jacques Chardonne ou l'incandescence sous le givre, op. cit.

4 Jacques Chardonne citado por Pol Vandromme.

5 Referimo-nos à problematização do conceito de Utopia na esteira do seu criador, o humanista Thomas More, como um lugar imaginário e puro onde existiria uma sociedade perfeita, ou seja, um lugar de projecção de um mundo irreal. Cf. Trousson (1999: 10).
} 
a estrutura matricial do género utópico. Sublinhe-se, a este propósito, que utopia e viagem são conceitos que não deverão ser dissociados já que alcançar "un pays imaginaire (Trousson, 1999: 10), uma "île inconnue" (Trousson, 1999: 21) ou um "pays de nulle part" (Trousson, 1999: 21) implicará sempre uma viagem como suporte indispensável à abordagem utópica.

A ligação com outras áreas do saber, nomeadamente, a Filosofia, poderá também orientar-nos para uma possível leitura da obra em análise através do modo como, sistematicamente, o narrador pensa e questiona a própria vida: "Est-ce l'accoutumance à l'évènement qui le transforme, est-il différent selon sa position dans notre vie? N'avons-nous qu'une idée des choses, une façon de les voir, que l'on pourrait diriger avec un peu de sagesse?" (Chardonne, 1953: 201), confessa o narrador numa das inúmeras reflexões que compõem o livro.

Vivre à Madère, título que dá nome à obra sobre a qual incide este ensaio, irá reenviar, de imediato, o leitor para o espaço onde se desenrola a acção, apesar de apenas as quarenta e cinco primeiras páginas, das duzentas e trinta e duas que constituem o livro, recorrerem à Ilha da Madeira como cenário da acção. Desprovido de intriga, "ce n'est pas une histoire exactement, que je vais écrire... C'est une route que je suivrai... Une route que tu reconnaîtras..." (Chardonne, 1953: 232), nele se encontrará um misto de reflexões e de lembranças onde se lança um olhar sobre os percursos de vida de um homem, (o próprio autor?), desde o passado até ao presente, evocando alguns dos seus escritores de eleição Nimier, Giraudoux, Apollinaire -, bem como experiências e episódios de vida onde desfilam figuras femininas descritas com detalhe. O narrador e protagonista - de quem nunca saberemos o nome -, sem deixar de aparentar algumas semelhanças com o autor empírico, irá viajar até à Madeira com o objectivo de localizar Charles Vergniol, seu amigo, "un homme grand [...], un peu philosophe de génie" (Chardonne, 1953: 92-93), que se havia mudado para a ilha em busca de calma e felicidade, longe das vicissitudes da vida:

Madère est une île semblable à un Éden. [...] C'est Charles qui m'en a parlé pour la première fois en 1936, quand il a décidé de quitter la France et d'aller vivre à Madère (Chardonne, 1953: 12).

Todavia, ao chegar à ilha, o protagonista irá confrontar-se com a notícia do (eventual) suicídio de Charles, sem razão aparente, no Cabo Girão, o segundo mais alto promontório da Europa, com seiscentos e vinte e três metros de altura:

nous prenons un sentier escarpé pour atteindre une plate-forme bordée par un parapet. Pinto ralentit le pas et me dit: «Vous aurez une surprise». C'est plutôt une 
suffocation, une gêne soudaine dans la poitrine et dans les yeux devant l'étrange épaisseur de vide glauque, six cent mètres à pic sur l'océan inerte, à peine grouillant sur ses bords au bas des rocs, et qui se confond avec le ciel [...]. «ll dit que M. Charles Vergniol s'est tué ici le mois dernier. On a trouvé son chapeau sur le mur, mais pas le corps. Cela vaut mieux. À Madère ce n'est pas permis de se tuer» (Chardonne, 1953: 28).

A busca empreendida pelo narrador com o objectivo de (re)encontrar Charles, o seu amigo, leva-o a deslocar-se à Ilha da Madeira para onde este se havia mudado há já alguns anos. Uma viagem no espaço que se parece desdobrar numa viagem ao interior do protagonista, dando a ver a experiência de um sujeito, simultaneamente Jacques Chardonne e Charles Vergniol, alter-ego do autor e personagem de ficção.

Dividido entre a filosofia de um homem solitário que anseia por vaguear por "une terre de l'oubli" (Chardonne, 1953: 11) e a convicção que tem de que a mulher contribui para que um homem se demita de si próprio, "ce sont les femmes qui sauvent l'esprit sur la face de la terre" ${ }^{\prime \prime}$ o protagonista, mas também narrador, deambulará não só pelo espaço, mas igualmente de mulher em mulher, desdobrando, dessa forma, a sua busca no espaço interiorizado de um eu:

Une grande déception dans la vie, c'est de vouloir rendre un être heureux sans y parvenir; et c'est l'autre qui ne vous le pardonne pas. Après tout, je ne sais lequel est le plus meurtri... (Chardonne, 1953: 224).

Por sua vez, a viagem que o protagonista irá empreender à ilha poderá encontrar ecos em viagens reais realizadas pelo autor empírico, uma possibilidade que se poderá ler na biografia de Jacques Chardonne, publicada por Ginette Guitard-Auviste, em 1984. De acordo com a autora, Chardonne terá visitado Portugal por diversas vezes, país que muito Ihe agradava, e de que guardaria muito boas recordações, das quais destaca o seu encontro com Amália Rodrigues. Igualmente importantes são as lembranças que guardou do percurso de Cascais a Ericeira, Sintra, "Quelle paix sur les routes de Cintra, dans le silence vierge, à l'ombre des arbres que l'on croit voir pour la première fois!" (Chardonne, 1953: 73), a Pousada de Óbidos, "centre de silence", onde lhe era possível reencontrar "les vestiges du bonheur terrestre, comme jadis en Charente" com todos", bem como a Madeira, ilha que lhe terá inspirado Vivre à Madère. Este autor terá visitado e permanecido na ilha, tendo conseguido decalcar para as páginas do seu livro a

\footnotetext{
${ }^{6}$ Correspondência de Jacques Chardonne. Citado por Ginette, Jacques Chardonne ou l'incandescence sous le givre, op. cit., p. 176.

${ }^{7}$ Chardonne citado por Ginette, Jacques Chardonne ou l'incandescence sous le givre, op. cit., p. 274.
} 
quietude interior e a serenidade de alma que, segundo confessou, se devia ao clima ameno e à hospitalidade dos seus habitantes.

Em 1951, Jacques Chardonne terá viajado de comboio até Lisboa, de onde partiria, posteriormente, para a Madeira, em hidroavião, um facto de que o autor dá conta na sua extensa correspondência, e que poderá ser reencontrado na ficção na forma como descreve a chegada do protagonista - ele próprio? - à ilha:

Cette année, je suis allé à Madère par hasard et tout à coup, parce que je me trouvais à Lisbonne. [...] J'ai quitté Lisbonne quand I'hydravion s'est décidé à partir, glissant quatre heures au-dessus d'une étendue de nuages blancs, percés de trous d'azur; l'hydravion se pose devant Funchal, capitale de Madère, après une descente dans les airs en beaux méandres qui font tournoyer les côtes rocheuses de l'île [...] On sait tout de suite qu'on est arrivé dans l'île des fleurs. Elles sont là, un peu exaltées, épanouies ensemble et de toute l'année, celles de France et celles d'Angleterre, celles de toutes les saisons (Chardonne, 1953: 17).

Um espaço que se abre à possibilidade de uma eventual ligação com outros tempos e com outros lugares do mundo, estimulada pela emoção decorrente da geografia dos lugares. A descrição da chegada do protagonista à ilha encontra ecos reais na vida do autor, um facto comprovado por Ginette Guitard-Auviste, autora da sua biografia, quando afirma:

il faut reprendre le cours du temps, revenir à l'année 1951 qui marque, chez ce sédentaire, la tentation des voyages. [...] Au début de mars, accompagné de Camille, il prend le train pour Lisbonne (il séjournera à Sintra) et, de là, emprunte I'hydravion de Madère, une aventure [...] Pourquoi Madère? Un vieux rêve, à ce qu'il semble. En effet, dès le 13 août 1930, il écrivait déjà à Géraldy: «Nous irons passer le mois de mars à Madère. Cet îlot à cinq jours de Cherbourg, à trois jours de Lisbonne ... [...] II rapporte, dans ses bagages, une idée de roman. Une idée très vague, qui ne prendra corps qu'à la longue et dont le cheminement l'étonne lui-même. (Guitard-Auviste, 1984: 261-262)

$\mathrm{Na}$ ficção encontram-se, assim, ecos de uma viagem real realizada por Chardonne à Madeira, confirmada por Ginette Guitard-Auviste, abrindo-se os horizontes da compreensão do texto onde se inscrevem experiências conservadas na memória, imagens como fragmentos poéticos de tonalidade autobiográfica, fazendo oscilar o discurso entre a realidade e o sonho, entre o real e o imaginário.

Embora tratando-se de estruturas distintas, a ficção parece sempre ir buscar ao real a sua verdadeira matéria romanesca para a investir dessa mecânica singular de pulsões, 
que exigirá uma recepção atenta do texto. Nesse processo, ela libertar-se-á também de uma sujeição ao real a que o texto apenas recorre para fundar o seu imaginário.

À semelhança de outras artes, a Literatura apropria-se dos espaços do mundo empírico, representando-os de acordo com o imaginário geográfico de cada autor. Submetido a um tempo e a um espaço particulares, este imaginário mantém uma inevitável ligação com paisagens reais desdobradas no texto, através de múltiplas formas, com as quais se poderá identificar.

Em Vivre à Madère, o autor oferece algumas das metáforas essenciais da representação da Ilha da Madeira na literatura e cultura locais, retraçando imagens mentais que representam o quotidiano da ilha bem como o dos seus habitantes: "On sait tout de suite que l'on est arrivé dans l'île des fleurs. [...] Les fleurs sont le culte du pays" (Chardonne, 1953: 18), declara o narrador aquando da sua chegada à ilha. Através da criação literária, determinados espaços serão mitificados como resultado do encontro com o sujeito que os percepciona. Os lugares evocados por Chardonne tendem a revelar a descrição de quem realmente terá assimilado o espírito do lugar: "Respire. C'est le parfum de Madère... une forte senteur un peu sucrée [...] vous monte à la tête..." (Chardonne, 1953: 229), dirá o autor nas últimas páginas do livro quando, de regresso a França e a casa, irá contemplar uma flor de magnólia. O interesse que a llha parece suscitar no autor assenta no carácter insular da sua geografia, no seu clima privilegiado e na beleza natural das paisagens, descritas com detalhe, em particular, a cidade do Funchal e os seus arredores Monte, e a costa sul: Câmara de Lobos e Ribeira Brava.

A obra, cuja intriga conduzirá o leitor de Lisboa à Madeira e a diferentes lugares de França, ilustra o que Guy Belleflamme denomina "la quête inassouvie du bonheur" (Belleflamme, 2005: 91), dando a ver o contraste entre a angústia e a esperança, aproximando-se de uma abordagem dos modos utópicos, na sua aspiração à felicidade, contudo, sempre por alcançar. O narrador esperaria reencontrar na ilha não só o amigo, mas também um lugar propício ao apaziguamento da sua alma e, consequentemente, alcançar a felicidade: "J'ai pensé alors que j'irai le voir [Charles]; avant de mourir je connaîtrai un paradis" (Chardonne, 1953: 12). Trata-se de uma busca não isenta de utopismos de uma sorte que, aparentemente, não existe anunciada, logo à chegada do protagonista à Madeira quando confrontado com a possibilidade do suicídio de Charles.

A incerteza acerca do destino do amigo que "lit dans l'avenir comme à livre ouvert" (Chardonne, 1953: 13), que afirmava "à Madère je serai tranquille" (Chardonne, 1953: 13), levará o narrador a persistir na busca da verdade, num primeiro momento, junto de uma excêntrica escritora, Mary Harrow, e posteriormente, instalado em Buc-Chalo, à beira do rio Sena, com a serena Ângela, viúva (ou não) de Charles, uma demanda pelo espaço desdobrada numa eventual busca interior do protagonista. 
Essa busca de sentido, implicada no seu trajecto, reenvia-nos para a modalidade de viagem dos tempos modernos a que se refere Adrien Pasquali em Le Tour des horizons, (Pasquali, 1994: 91) segundo a qual, o reconhecimento do mundo exterior deixa de constituir o objectivo principal do viajante, mais motivado pelo conhecimento de si próprio. Nessa obra, Pasquali aporta a sua perspectiva sobre o facto de que para o homem do século XIX, a tópica da viagem passar a incidir na descoberta do eu interior em substituição da descoberta e conquista do espaço exterior.

Jacques Chardonne, que não será de todo alheio a essa abertura à viagem interior nas viagens dos heróis que ele encena, privilegiará, sobretudo, momentos da existência em detrimento da percepção e descrição de itinerários. Segui-los, ao longo desse percurso, significará acompanhar a sua transformação, um processo que a própria viagem parece já implicar, se atentarmos na sua definição, nomeadamente a que Maria Alzira Seixo propõe, considerando como um traço dominante dessa tópica, a transformação do sujeito relacionada com a aprendizagem no tempo e no espaço que the: "possibilit(a) [...] viver uma aventura, que constituirá a sua aprendizagem [...] como condição da sua transformação" (Seixo, 1991: 833), uma perspectiva que virá emergir no contexto ficcional de Chardonne quando afirma, pela voz do narrador que "[...] regardant un bateau, je songe à me purifier tout à fait par un voyage au long cours [...] le cri de la délivrance" (Chardonne, 1953: 72).

O barco, metáfora da "longa" viagem, assumir-se-á como veículo para uma eventual mudança e consequente "purificação" do sujeito da enunciação, veiculada por esse "cri de la délivrance". Conhecer e dar a ver a diferença de um mundo novo, já não será o objectivo fundamental, mas sim, para Chardonne, a descoberta e a apreensão do mundo interiorizado:

Satisfaire nos goûts, vivre à notre gré, sont prétentions courantes; pourtant rien n'est plus incertain, parfois moins personnel, que nos goûts si impérieux en apparence. (Chardonne, 1953: 99).

É nesta perspectiva que, para o autor, a temática da viagem se configura a partir de um conjunto de experiências e de transformações interiores operadas pela deslocação da personagem no espaço, a fim de lhe permitir, em última instância, aceder a uma realidade outra. A personagem desloca-se, mas para se fixar num outro lugar, mergulhada numa espera que a levará a perfazer a sua transformação e, assim também, a problematizar a viagem contrária aos pressupostos do dinamismo de uma viagem canónica. A deslocação, que possibilita a transformação (interior) do viajante, só encontrará o seu verdadeiro sentido através desse momento de espera, de duração, de amadurecimento: "[...] la mer commence dans un encadrement de colonnes et, regardant un bateau, je songe à me purifier tout à fait 
par un voyage au long cours" (Chardonne, 1953: 72). Um percurso desenhado nas múltiplas deslocações feitas pelo narrador ao longo do texto que culminará na aparente serenidade encontrada no desfecho do livro. Uma aparente serenidade, porque inacessível, tendo em conta a natureza e essência da própria busca: "J'ai cherché les paradis sur la terre, et d'abord dans l'amour", dirá Chardonne no incipit do livro, precisando logo adiante que "c'est une terre de l'oubli que je désire [...] Madère est une île assez semblable à un Éden" (Chardonne, 1953: 11).

Todavia, condenado a viver na esperança, o homem parece jamais encontrar 0 «paraíso» por que tanto anseia. O que se afigurava esperança na promessa de encontro e de realização culminará na decepção do desencontro veiculada pelo eventual suicídio de Charles e na conclusão do protagonista ao afirmar:

- Non, on ne peut pas vivre à Madère.

Je vais vous dire quelle est la malédiction de l'homme : il est rétif au bonheur, il n'a pas de perceptions, sinon fugaces, pour les choses belles ou délicieuses ; il gâte tout pour un esprit insatiable, malsain, pétri dans le malheur (Chardonne, 1953: 37-38).

A permanente busca de felicidade inerente à natureza do Homem, descrita na abordagem da utopia, parece sempre movê-lo em busca de um lugar imaginário, um "paradis terrestre" (Trousson, 1999: 21). Para Jacques Chardonne, esse lugar afigurava-se a Madeira, a ilha para onde Charles se havia mudado. Todavia, a decepção do desencontro levá-lo-á a concluir que o paraíso não existe e que apesar da esperança que sempre habita o homem, "il est rétif au bonheur". Uma esperança que, afinal, parece apenas residir no carácter de transitório que ela tem. 


\section{Bibliografia}

Belleflamme, Guy (2005). "Variations madériennes". In : Franco-phonie vivante, no 2, juin. Belgique: Hayez Imprimeurs.

Chardonne, Jacques (1953). Vivre à Madère. Paris: Éditions Bernard Grasset, Coll. Les Cahiers Rouges

GUITARD-AUVISTE, Ginette (2000). Jacques Chardonne ou l'incandescence sous le givre. Paris: Albin Michel

PASQUALI, Adrien (1994). Le tour des horizons. Paris: Klincksieck

SEIXO, Maria Alzira (1991). "A Tópica da Viagem no Livro do Desassossego". In: Estudos Portugueses. Homenagem a Luciana Stegagno Picchio. Lisboa: Difel, p. 833.

Trousson, Raymond (1999). Voyages aux pays de nulle part. Bruxelles: Éditions de l'Université de Bruxelles.

VANDROMme, Pol (2003). Chardonne c'est beaucoup plus que Chardonne. Paris: Éditions du Rocher. 